\title{
Kitap Değerlendirmesi: ed-Dûrî, Abdülâziz. Abbâsîler Tarihi (Siyasî, İdarî, Sosyal ve Ekonomik Açıdan), Tercüme: Kasım Koç, (İstanbul, Beka Yayıncilık, 2020). ISBN: 978-605-7828-11-8
}

\section{Enes Ensar Erbay* (1)}

Değerlendirmesini yaptığımız çalışma, Abdülâziz ed-Dûrî'nin (1919-2010) el-Asru'lAbbasiyyu'l-evvel: Dirâse fi 't-târîhi 's-siyâsî ve'l-idârî ve'l-mâlî (Bağdat 1945, Beyrut 1988, 1997, 2006, 2007, 2009) ve Dirâsât fi'l-usûri'l-Abbâsiyyi'l-müteahhire (Bağdat 1949, Beyrut 2007, 2011) isimli kitaplarının tercüme edilip tek cilt halinde yayımlanmasıyla oluşturulmuştur. Dûrî’nin bu iki kitabı, farklı yayın evleri tarafından birkaç kez yayımlanmıştır. Ancak tercümede, söz konusu kitapların hangi baskılarının dikkate alındığına dair bir kayıt bulunmamaktadır. Bu nedenle tercümeyi değerlendirirken kitapların ilk basımlarını (Bağdat 1945 ve 1949) incelemekle birlikte el-Asru'l-Abbasiyyu'l-evvel kitabının 2009, Dirâsât fi'l-usûri'l-Abbâsiyyi'l-müteahhire kitabının ise 2011 Merkezü'd-Dirâsâti'l-Vahdeti'lArabiyye basımını esas aldık. Mütercimin, ilk kitabı "Siyâsî, İârî, Sosyal ve Ekonomik Açıdan Abbâsîlerin Birinci Dönemi" olarak; ikinci kitabı ise "Siyâsî, İdarî, Sosyal ve Ekonomik Açıdan Abbâsîlerin İkinci Dönemi” ş̧eklinde çevirdiği görülmektedir. Halbuki ilk kitabın (el-Asru'l-Abbasiyyu'l-evvel: Dirâse fi 't-târîhi's-siyâsî ve'l-idârî ve'l-mâlî) "Abbâsîler' in İlk Çağı: Siyâsî, İdârî ve Mâli Târih Açısından Bir Araştırma", ikinci kitabın (Dirâsât fi'l-usûri'l-Abbâsiyyi 'l-müteahhire) ise "Geç Abbâsî Çağları Üzerine Araştırmalar" şeklinde tercüme edilmesinin daha doğru olduğu kanaatindeyiz. Zira kitabın müellifi Dûrî’nin, Abbâsî tarihini Birinci ve İkinci şeklinde dönemlere ayırma gibi bir işleme karş1 olduğu bilinmektedir. ${ }^{1}$ Ayrıca kitabın Arapça aslında mevcut olmayan Birinci ve İkinci gibi ifadelerin Türkçe metne yerleştirilemeyeceği de eklenmelidir.

1 Abdülazîz Dûrî, İlk Dönem İslam Tarihi -Bir Önsöz-, Endülüs Yayınları, İstanbul 2016, Çev.: Hayrettin Yücesoy, s. 30-31. 
Kitabın başlığından da anlaşılacağı üzere Dûrî, Abbâsî tarihini tüm yönleriyle kuşatacak bir bakış açısı sunmak istemektedir. Bu sâikle oluşturduğu planın mezkûr amaca mâtuf olduğu anlaşılmaktadır. Zira salt siyâsî tarih aktarımından ziyâde o, toplumun bileşen unsurlarını, mezhebî faktörleri, vergileri, hatta saray içi idârî meseleleri de eserine konu edinmiştir. Özellikle vergilere, vergilerle ilintili olarak İsmailî-Karmatî hareketlere uzunca değiniyor olması, yazarın uzmanlık alanıyla doğrudan ilgilidir. Yazar, iktisâdî faktörün siyâsî-dinî ve toplumsal çerçevenin şekillenmesinde belirleyici bir rolünün olduğunu, kurduğu metnin planında ihsas ettirmektedir. Bu yönüyle o, mevcut kronolojik siyâsî tarih yazımından ayrılmaktadır. Tercümenin iki ana kitaptan müteşekkil olduğunu yukarıda ifade etmiştik. Siyâsî, İdarî, Sosyal ve Ekonomik Açıdan Abbâsîlerin Birinci Dönemi isimli tercümenin ilk bölümü, bir önsöz ve on bir ana başlıktan oluşmaktadır. Siyâsî, İdarî, Sosyal ve Ekonomik Açıdan Abbâsîlerin İkinci Dönemi isimli ikinci bölümü ise bir önsöz, sekiz ana başlıktan oluşmaktadır.

Dûrî'nin, doktora tezinde Irak'ın ekonomik hayatı üzerine yoğunlaşması, bu çalışmasında vergiler çerçevesinde daha ayrıntılı çıkarımlar yapmasını sağlayan bir unsur olmuştur. Bu açıdan onun, vergilerin ağırlığının küçük toprak sahibini büyüğüne muhtaç bıraktığı yönündeki tespiti değerlidir (s. 23). Küçük mülk sahibi, bu adımla bir hâmiye ihtiyaç duymuş; zamanla da mülkünün elinden gittiğine şahit olmuştur. Anlaşılan o ki bu durum, Abbâsî ihtilâline giden yolda iktisâdî âmillerin başında gelmektedir. İhtilâlin çıkış noktasının Horasan olmasıyla ilgili yazar bir yorumda bulunmaktadır. Buna göre Horasan'da sınırlı sayıda 'Pers milliyetçisi' bir ruhun var olması, onların Emevîler'e karşı Hâşimîler'i desteklemelerini sağlamıştır. 'Pers milliyetçileri' önce Emevîler'den kurtulacak; sonra da gü̧̈ mevâlinin -kendilerinin- ellerine geçince hedefleri için çalışacaklardır (s. 26). Bu değerlendirme, kullanılan ıstılahta anakronizme düşüldüğünü göstermektedir. Zira milliyetçiliğin henüz bir düşünce olarak belirmediği, ulus/millî benlik bilincinin karşı1ık bulmadığı bir dönem için bu tarz yorumların oturaklı olmadığı ifade edilmelidir. Mezkûr terim yerine alternatif değerlendirmelere gidilebilir. Örneğin dönemin en yaygın meşrûiyet unsuru olarak kabul edilen ve dolayısıyla siyâsî hükmün hanedanlar üzerinden inşâ edilmesini sağlayan 'nesep/soy taassubu' kullanılabilirdi.

Abbâsî dâveti esnâsında dâilerin amaçlarını gerçekleştirebilmek için çeşitli ilke ve kabullerinin olduğu, Propaganda'nın Faydalandĭ̆ İlke ve İnançlar başlığı altında zikredilmektedir. Buna göre mevcut vetirede Emevî Devleti'nin içerisinde bulunduğu kargaşa ortamı, kehanet ve tenebbü (gaybten haber verme) anlayışının tesiri, İslâm'a aykırı olan fakat özellikle Horasan'daki halk yığınının inançları 
arasında yer alan ruh göçü ve hulûl gibi kabuller, Pers milliyetçiliği ${ }^{2}{ }^{2}$ iktisâdî vaziyetin negatif etkisi ve Ehl-i Beyt'in ağırlığı, ihtilâlin başarıya ulaşmasında etkili olan unsurlar olmuştur (s. 43-47). Bu etkiler incelendiğinde şu çıkarımlar yapılabilir:

1- Abbâsî dâilerinin siyâsî gâyeler odağında maslahat itibariyle dinî kabullerden birtakım tavizler verdiği anlaşılmaktadır.

2- Mevâlî’ye yönelik küçümseyici tutumda değişim süreci başlamıştır.

3- Ehl-i Beyt' in siyâsî vasfi, ihtilâlin gerçekleşmesi yönüyle işlevsel bir nitelik kazanmıştır.

Yazar, Abbâsî ihtilâlinin sonucunu değerlendirdiği Emevîler'den Abbâsîler'e Geçişin Anlamı isimli bölümün yedinci maddesinde, yeni kurulan Abbâsî Devleti'nin başkentini Şam'dan Irak'a taşımasını, Irak'ın Şam'a galibiyeti olarak yorumlamaktadır. Bu okuma biçimine bir alternatif getirmek mümkündür: Emevîler döneminde Şam-Doğu Roma ekseni üzerinden coğrafî konumunu belirleyen ve etkinliğini burada arttıran siyâsî güç, artık Irak-Sâsânî coğrafyasında faal bir konuma yükselmiştir. Zira Horasan'daki siyâsî vaziyet, Şam'dan çok daha belirleyici olmuştur. İfade ettiğimiz bu fark, oryantalist Doğu Roma-Sâsânî müessese ve kurum tesiri anlayışından uzak tutularak değerlendirilmelidir. Burada, coğrafî faktörlerin bölge üzerindeki etkisi çerçevesinde bir farka değinilmek istenmiştir. Nitekim bu coğrafî etkinin bir neticesi olarak hilâfet topraklarının yeni başkentinin ismi dahi, Fârisî menşeli bir kelimedir. ${ }^{3}$

Abbâsîler'in Orta Asya'daki Zaferi başlığı altında kısa bir paragrafla Talas Savaşı'na ${ }^{4}$ değinen yazar, savaşın Araplar tarafından kazanılmasıyla, Mâverâünnehir bölgesinde Çin medeniyeti yerine Arap medeniyetinin hâkim olduğu yorumunda bulunmaktadır. Burada değerlendirilmesi gereken iki temel husus vardır:

1- Savaş, Abbâsîlerle bazı Türk boylarının ittifakı neticesinde kazanılmıştır. Fakat metinde Türklere dair herhangi bir atfa rastlanılmamaktadır.

2- 'Arap medeniyeti' terkîbinden beyânın ne olduğu hususunda bir anlam kapalılığı söz konusudur. Kuvvetle muhtemel müellifin Arap medeniyeti terkibinden kastı, İslâm medeniyetidir. Lâkin tercümede bunun izâhı sunulmamıştır.

Halife Mehdi (158-169/775-785) döneminde zındıklara yönelik bir kovuşturma faaliyeti başlatıldığı, bunun esasen halifeye babası Mansur (136-158/754-775) tarafından vasiyet yoluyla ödev bırakıldığı Mehdî Devri başlı̆̆ındaki bilgilerden anlaşılmaktadır (s. 110). Halife Mansur onları, çeşitli vasıflarıyla tanıtıp oğlunu

2 Bu ifadeye katılmadığımızı yukarıda belirttik.

3 Abdülâziz ed-Dûrî, "Bağdat", TDV İslâm Ansiklopedisi, https://islamansiklopedisi.org.tr/bagdat (Erişim 09.11.2020).

4 Savaşın ismi yazar tarafindan belirtilmemiştir. 
bu hususta uyarmaktadır. Halife Mansur döneminde bastırılan muhalif unsurlar, tanınmamak ve faaliyetlerini yürütmeye imkân bulabilmek amacıyla sessiz ve gizli gruplara bürünerek işlevselliğini korumuşlardır. Dûrî, zındıklık cereyânlarını Abbâsîler ile yine 'Pers milliyetçileri' arasındaki ilişkinin tabiî bir sonucu olarak yorumlamaktadır (s. 110-112). Burada, siyâsî erkin paylaşımı çerçevesinde bir yorumda bulunulabilir. Buna göre, ihtilâlde Abbâsoğulları'nın yanında yer alan bu gruplar, ihtilâlden sonra -Ebû Müslim el-Horasanî’nin (ö. 137/755) de katledilmesiyle-kurulan devlet içerisinde faaliyet alanı bulamamışlar; dolayısıyla kendilerine yeni hareket sahası açmaya çalışmışlardır. Mehdi devri için diğer bir önemli nokta, babası Mansur'a kıyasla daha sakin bir dönem geçirmiş olması, fakat babasının aksine vezirleri devlet işlerinde daha etkin bir konuma yükseltmesi, hatta Ya'kûb b. Dâvûd'a tüm işlerin idâresini teslim etmesidir. Bu siyasetiyle onu otoriteden ilk taviz veren Abbâsî halifesi olarak nitelemek mümkündür. Mehdî’nin hazinedeki parayı bitirdiğini aktaran yazar, onun bayındırlık faaliyetlerine yaptığı harcamaları da zikretmektedir. Yeni kurulan devletin yol, kanal, berîd, hayır faaliyetleri gibi eksikliklerinin temelden inşâ edilmesi, bu harcamaların sarf edildiği yerin açıklayıcısı olabilir.

Yazar, Hârûnürreşîd'in (169-193/786-809) Şiîlerle olan ilişkisini 'makyevalist' (doğru yazım: makyavelist) bir politika olarak değerlendirmektedir. Kullanılan bu terimin Hârûnürreşî̉'in yaşadığı dönem için uygun olmayacağı ifade edilmelidir. Zira bunun anakronik bir değerlendirme olacağı açıktır. Bunun yanında Emîn (193198/809-813) ve Me'mûn (198-218/813-833) arasındaki hilâfet kavgası çerçevesinde bir değerlendirmede bulunmak gerekmektedir. Özellikle Emîn'in şahsiyetine dair oluşan olumsuz rivayetlerin, yazara göre sorgulanması gerekmektedir (s. 171-172). Zira bu konuda birbirini nakzeden görüşler bulunmaktadır. Yazarın bu değerlendirmesi haklı ve yerindedir. Zira tarihin yazımı, kazanan muktedirin eliyle olmuştur. Siyâsî üstünlüğü kaybeden mağlup, -Emîn'in şahsiyetine dair çokça kullanılan olumsuz rivayetler gibi- galibin betimlediği biçimde ele alınmıştır. Bu açıdan Emîn'e dair İslâm tarihi kaynaklarında çizilen tasvirin, onun siyâsî mağlubiyetiyle birlikte değerlendirilmesinin yerinde olacağını düşünüyoruz. Lâkin yazarın bu argümanı sunarken bir çelişki içerisinde bulunduğunu eklemek gereklidir. Zira o, Emin'i akıllı, kültürlü ve bilgin bir kimse olarak tanımladıktan sonra onun, çevresinde bulunan bürokratların entrika ve oyunlarına gelerek kardeşi Me'mûn'la arasını bozduğu şeklinde bir değerlendirmede bulunmaktadır (176-177). Emîn, bilgin ve zeki bir idâreci ise bu entrikalara kanarak kardeşiyle arasını nasıl bozmuştur? Özellikle Fazl b. Rebî‘in (ö. 208/823-24[?]) telkin ve yönlendirmelerine kapıldı̆̆ yönündeki rivayetlerin aktarımı ile onun bilgin ve akıllı bir idâreci olduğu yorumları çelişki arz etmektedir. Bu açıdan mezkûr rivayetlerden biri seçilmeli; diğeri tahlil edilerek yorumlanmalıdır. 
Mu'tasım Billah (Ebû İshâk Muhammed Devri) bölümü içerisinde Mu'tasım'a (218-227/833-842) dair çeşitli şahsî özelliklerin sunulduğu bir paragrafta mütercimin Mu 'tasım'1 sehven 'Me'mun' olarak kaleme aldığı görülmektedir (s. 210). Arapça metinde ise ilgili pasajda Mu'tasım ismi zikredilmektedir. ${ }^{5}$ Afşin' in (ö. 226/841) Bâbek (ö. 223/838) ile olan savaşında Ermeniyye'deki güç sahiplerine mektuplar gönderdiğinin ifade edildiği pasajda, Arapça metinde yer alan 'B1trîk (بطريق)' kelimesinin doğrudan 'Patrik' olarak tercüme edildiği göze çarpmaktadır (s. 220). Cevherî (ö. 400/1009'dan önce), ${ }^{6}$ Zeynüddin er-Râzî (ö. 666/1268), İ İbn Manzûr (ö. 711/1311) ${ }^{8}$ ve Murtaza ez-Zebîdî’nin (ö. 1205/1791) ${ }^{9}$ kelimeye 'komutan, savaşç1, savaşta becerikli kişi' gibi anlamlar verdiğini görüyoruz. Bu nedenle 'Bıtrîk (بطريق)' sözcügüuyle ifade edilmek istenenin 'komutan, savaşçı' olduğunu belirtmeliyiz. Metnin genel yapısından ise bu terimin, Ermeniyye'nin güç sahibi Hristiyan prensleri için kullanıldığ anlaşılmaktadır. ${ }^{10}$ Bunun yanında yazarın Afşin' in mücadele içerisinde olduğu Hürremiyye'yi ortakç1/sosyalist (إنشتر اكية) şeklinde nitelediği görülmektedir (s. 223). Buradaki 'İştirâkî' ifadesinin 'sosyalist’ terimi ile tanımlanması yine anakronik bir yaklaşımı gündeme getirmektedir. Bu açıdan tercümede sadece 'ortakçı' terimi ifade edilmesi, daha yerinde bir kullanım olabilir.

Yazar, bilhassa merkezî idâreye taallûk eden değerlendirme ve yorumlarında muhafazakâr bir anlayış çizmektedir. Bu muhafazakâr tutum, merkezî idârenin fiil ve tasarruflarını bir anlamda mutlak ve doğru, muhâlif hareketlerin girişimlerini ise ayrılıkçı, dolayısıyla yanlış ve zararlı gören bir tarih okuma biçimi olarak açıklanabilir. Hassâten Türkler ve İranlıların devlet içerisinde varlık sahası buldukları süreçlere dair birtakım izahların olduğu müşahede edilmektedir. Horasan merkezli

5 Abdülâziz ed-Dûrî, el-Asru'l-Abbâsiyyu'l-Evvel (Dirâse fì't-Târihi's-Siyâsî ve'l-İdârî ve 'l-Mâlî), (Beyrut: Merkezü'd-Dirâsâti'l-Vahdeti'l-Arabiyye, 2009), s. 231.

6 Ebû Naṡr İsmail b. Hammâd el-Cevherî, Tâcu'l-Luğa ve Ṡ̉hâhhu'l- 'Arabiyye, nşr. Aḥmed 'Abdulğafûr 'Aț̣âr, (Beyrut: Dâru'l' İlm li'l-Melâyîn), IV/1450.

7 Ebû 'Abdullâh Muḥammed b. Ebî Bekr b. 'Abdulḳâdir Zeynuddîn er-Râzî, Muhtâru's-Ś̉hâhh, nşr. Yûsuf eş-Şeyh Muhammed, (Beyrut: el-Mektebetu'l-'Aṡriyye, ed-Dâru'n-Nemûẑeciyye), s. 36 .

8 Ebû'l-Faḍl Muhammed b. Mukerrem b. 'Alî Cemâluddîn İbn Manẓûr, Lisân'l- 'Arab (Beyrût: Dâru Sâdir), X/21.

9 Muḥammed b. Muḥammed b. 'Abdurrezzâk ez-Zebîdî, Tâcu'l- 'Arûs min Cevâhiri'l-Kâmûs, nşr. 'Alî Şîrî, (Dâru'l-Fikr), VI/461.

10 Taberî Tarihi'nin İngilizce tercümesinde 'Bıtrîk (Bıtriq)' sözcüğü için yapılan açılama, bu yorumu destekler niteliktedir. Kelimenin bir Doğu Roma (Byzantine) unvanı (Patricius) olduğunu belirten Taberî mütercimi, Doğu Roma soylularıyla eşit olduğunu düşünen Ermenî prenslerinin bu unvanı kullandıklarını eklemektedir. Bkz.: Abu Ja'far Muhammad b. Jarir al-Tabari, The History of-al-Tabari- Ta'rikh al-rusul wa'l-muluk, Translated by C. E. Bosworth, (New York: State University of New York Press, 1991), XXXIII/72. 
çıkan her isyânı İranlılar/Fârisîler çerçevesinde eski Pers gücünü geri getirmeyi hedefleyen bir organize olarak ele almış ve bu çerçevede yorumlarda bulunmuştur (s. 87-88, 265). Bu yorumlarda kabul edilebilecek doğruluk payı bulunmakla birlikte, bölgede çıkan ilk isyânların (Sünbaz el-Mecûsî, Üstâz Sìz, Yûsuf el-Berm, Mukanna', Ali Mazdek, Bâbek el-Hürremî) dinî -veya mezhebi- iktisâdî ve daha başka kabullerden kaynaklanan bir çıkış noktası da söz konusudur. Bu açıdan bu tarz hareketlerin, siyâsî amaçlarla yola çımış olsalar da salt siyâsî sebepler üzerinden değerlendirilmemeleri gerekir. Esasen yazarın kurduğu ve uygulamaya çalıştığı plan, iktisâdî, toplumsal, dinî ve siyâsî pek çok kategoriyi barındırmasına rağmen -bu örnekte olduğu gibi- bazen tüm argümanları bir disiplinin (siyâset gibi) merkezinde değerlendirdiği görülebilmektedir. Örneğin Fazl b. Sehl'e (ö. 202/818) dair yorumları da bu minvalde ele alınabilir. Yazarın Fazl b. Sehl'i çok fazla önemsediği, metinde onun için ayırdığı bölüm ve pasajlardan anlaşılmaktadır. Anlaşılan o ki tarihi, merkezden, bir anlamıyla aslî unsur (Arap-İslâm) üzerinden okumayı tercih eden Dûrî'ye göre Arap dışı olan Fazl'ın devlet için karşılığı, daima plan kuran, Persçi bir hedef güden, Sâsânîler'i taklit eden (s. 195-197), dolayısıyla -merkez için yorumlandığında- tehdit teşkil eden bir unsur olmasıdır. Şuûbiyye hareketi ile edebî alana da yayılan bu mücadele, yazar tarafından dinî, siyâsî, edebî ve hatta iktisâdî alanda Persler tarafından açılan bir savaşın varlığı olarak ele alınmaktadır (s. 265). Dikkat edilirse yazar, daima hilâfet merkezinin karşılaştığı tehditleri açıklamak üzere bir anlatım tercih etmektedir. Onun tarih okuma biçiminde fark ettiğimiz en belirgin husus, hâkim unsurun ve merkezî otoritenin var oluş ve hakl1lığının esas kabul edildiği, İslâm toplumuna sonradan katılan güç ortaklarının ise fitne ve yıkılışa sebep olan ana âmiller olarak değerlendirildiği yönündedir. Tarih yapma-yazma biçimiyle doğrudan alâkalı olan bu husus, farklı çalışmalarda üzerine gitmeyi hak eden bir görünüm çizmekle birlikte, eserde tarihçinin analizlerinin tutarlılığını zedeleyici bir etki bırakmıştır.

Zındıkların Takibi başlı̆ğ altında zındık hareketlerin gayesine bir örnek vermek için yazar, Halife Mu'tasım'ın komutan Afşin için 'Pers saltanatını ve Mecûsî dinini geri getirme' şeklindeki iddialarını ileri sürerek onun siyâseten bu hedefi güttügünüü iddia eder (s. 112). Bu iddialar çerçevesinde Afşin'in de Zenâdıka'ya mensup olduğu yönünde bir sonuç çıkmaktadır. Yazarın da vurguladığı gibi 'hasımları yok etme aracı olarak' zındıklık isnâdı, o süreçte elverişli bir kullanımdır lâkin Afşin için bu kaydı düşme gereği görmemiştir. Bunun yanında yazar, Browne'a atıfla Afşin'i eski Pers krallarına mensup bir İranlı olarak tanımlamaktadır (s. 227). ${ }^{11}$

11 Edward Granwille Browne, Bâbek ve Mazyâr'ın isyânlarına bir benzetme yaparak, Afşin'in de en az onlar kadar Pers olduğunu iddia etmektedir. Bkz.: Edward Granwille Browne, Literary History of Persia, Cambridge University Press, I, 1956, s. 330-331. 
Halbuki onun Türk olduğuna dair güçlü deliller bulunmaktadır. Hakk1 Dursun Yıldı'ın (1937-1992) bu husustaki çalışmaları, Afşin'in Türk olduğu noktasında bir kanaatin yerleşmesini sağlamıştır. ${ }^{12}$ Yazarın Türkler hakkındaki iddiaları ise, makul değerlendirmeler olarak ele alınamaz. Zira onun yorumları, yer yer Arap milliyetçisi bir tasvir çizmektedir. Şüphesiz bu, çağının ideolojik milliyetçi perspektifinden bağımsız bir tutum değildir. Onun yaşadığı sürecin, -tarihçinin yorumuna etki gücünü göstermesi açısından- örnekleyebileceğimiz ve mâkul değerlendirmeler haricinde tutulması gereken ifadelerini şu şekilde alıntılayabiliriz:

“....Persler, Abbâsîlerin medenî ilerlemesine yardımcı olan kurumlara ve geleneklere sahip medenileşmiş bir millet iken, Türkler bunlardan mahrumdu. Câhız, onlarl "acemlerin bedevileri" şeklinde adlandırlyor ve ziraata, sanata, zanaata ve kültüre ilgi ve sevgi duymadıklarını belirtiyor..." (s. 211)

“.....Persleri ve Arapları ihmal ederken sadakati de kültürü de olmayan ve kazançtan başka bir şeye önem vermeyen insanları kendine yakınlaştırdl...” (s. 239)

“....Zira Türkler, o zamanlarda tek üstün niteliği askerî cesareti olan bedevî bir halktı... ”(s. 266)

Halife Muktedir devri, Abbâsî hilâfetinin siyâsî seyri açısından önemli sonuçları olan bir dönemdir. Zira babası Mu'tazıd (279-289/892-902) ve ağabeyi Müktefî (289-295/902-908) döneminde ordu ve diğer güç blokları karşısında nisbeten daha fazla güçlenen hilâfet, Muktedir devrinde zaafa uğramıştır. On dört kez vezir değişikliğine giden (s. 384) Muktedir'in siyâsî çıkmazı, değiştirdiği vezir sayısından da anlaşlabilmektedir. Büveyhî idâresinin kurucuları olan Ali, Hasan ve Ahmed kardeşlerin; siyâsî zaferlerini desteklemek amacıyla Sâsânî hükümdarı Behrâm-1 Gûr'a (420-438) veya onun veziri Mihr-i Nersî’ye uzanan bir nesep uydurmaları (s. 416-417), nesep oluşturmanın politik bir gaye olduğu çıkarımını yapmamızı sağlamaktadır. Diğer yandan bu durum, yazarın 'Pers milliyetçiliği' iddiasını yeniden sorgulamamıza imkân sağlamaktadır. Zira Deylemî olduğu bilinen Büveyhîler’in, siyâsî meşrûiyet için Pers kimliğini -dolayısıyla millî benliğini- öne çıkarmaktan ziyâde kendilerini yüksek bir hanedanın veya o hanedanın vezirinin soyuna ait

12 Yıldız'a göre Afşin'in Fârisî olarak kabul edilmesinde en büyük etken, baba adının bir Fars ismi olan Kâvûs olmasıdır. Lâkin bu, ona göre ciddi bir delil teşkil etmemektedir. Zira Müslüman olmadan önce Mecûsî olan Afşin ve babası, Fars kültüründen etkilenerek bu ismi almıştır. Diğer yandan Üsrûşene'yi Türk hanedanların yönettiği, Afşin'in de bu hanedana mensup olduğu tarihî kayıtlar arasındadır. Ayrıca Ya'kûbî'de geçen bir habere göre onun dayı oğlunun Mengü-çur olması, bu ismin ise bilinen Türk isimleri arasında yer alması önemli bir delildir. Bunlara ek olarak Türk memlüklerin Abbâsî devletinde asker statüsünde görev almaya başladıkları bir kertede Afşin'in de bir komutan olarak zuhur etmesi tesâdüfî olmayacaktır. Bkz.: Hakkı Dursun Y1ldı, İslâmiyet ve Türkler, (İstanbul: İlgi Kültür Sanat, 2011), s. 139-141, Hakk1 Dursun Y1ldız, "Afşin”, TDV İslâm Ansiklopedisi, https://islamansiklopedisi.org.tr/afsin-haydar-b-kavus (Erişim 15.11.2020). 
olarak göstermeye çalışmaları, 'nesep/soy taassubu' anlayışının siyâsî meşruiyet unsuru olarak mevcut konjonktürün temel belirleyicilerinden biri olduğunu gösterir.

Türkçede Abbâsîler üzerine genel tarih yazımının azlığı düşünüldüğünde bu metnin okuyucu kitlesine faydasının olacağı kabulümüzdür. Lâkin yazarın mezkûr çalışmayı tamamladığında henüz 25-30 yaşlarında olması ve eserin diğer basımlarında kayda değer bir değişiklik yapmaması, çalışmanın ciddi bir tahkike ihtiyaç duyduğunun en belirgin göstergesidir. Genç yaşlarında Abbâsî tarihi yazımına girişen yazar, yaşadığı sürecin akademik gündeminin temel mevzularını eserinde işlemiş, muâsır kaynaklara çokça atıf yapmıştır. Fakat kitabın yazıldığ 1 tarihe (1944-1949) kıyasla bugün, mezkûr alanda gözle görülür bir literatür oluşmuş, yeni kaynaklar bulunmuş; hatta yazarın metninde ele aldığı birtakım kabuller de yeni bulgular 1şığında değişmiştir. ${ }^{13}$ Eserin bu gözle değerlendirilmesi, içerisinde yer alan yorumların dengelenmesinde önemli bir etken olacaktır. Tercümenin ileriki basımlarında girişte yazarın hayatına dair bir biyografi bilgisi, sonunda ise okuyucuların istifadesini artırmak amacıyla bir indeks konulması faydalı olacaktır. Kitapların Arapça son baskılarında eserin sonuna fihrist eklendiği görülmekle birlikte bunun tercümeye dahil edilmediği görülmektedir. Bunun yanında tercüme edilen kaynakçanın istifade imkânını oldukça sınırlı tutan bir yapısının olduğu ifade edilmelidir. Son baskılarında süreli yayın ve kitap ayrımı, Arapça ve yabancı dildeki eserlerin kaynakçada birbirinden ayrı zikredildiği görülmekle birlikte bu tasnife tercümede riayet edilmediği eklenmelidir. Diğer yandan tercümede ve kavramlarla ilgili Arapça ifadelerin transkripsiyonunda hatalar görülmüştür. Akademik yazıma daha uygun olması açısından ilgili tercüme ve transkripsiyon hatalarının doğru kullanımlarını belirtmeyi uygun gördük.

\section{Metnin Aslı}

فلم يرض عبد الملك بن مروان بذاللك و بعث إلى عامله

\section{Mütercimin Tercümesi}

Ama Abdülmelik b. Mervân, buna razı olmayıp valisine elçi gönderdi. (s. 20)

\section{Teklif Edilen Tercüme}

Abdülmelik b. Mervan buna razı olmadı ve âmilini gönderdi.

13 Bu kaynakların bibliyografya halinde genel bir sunumu için bkz.: Levent Öztürk, İsmail Hakkı Atçeken, M. Bahaüddin Varol, Mustafa Demirci, Mehmet Azimli, Saim Yılmaz, Şaban Öz, Ali Dadan, “Abbâsîler Dönemi Bibliyografyası”, İstem, 6/12: 2008, s. 287-329. 
Metnin Aslı

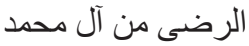

Mütercimin Tercümesi

Âl-i Muhammed'den Rizâ (s. 35)

Teklif Edilen Tercüme

Muhammed ailesinden râzı olunan kişi

Metnin Aslı

رأى الرشيد أن يرفق بالعلويين، و أن يزيل أثر سياسة الهادي العنيفة

\section{Mütercimin Tercümesi}

Harun Reşîd, Şiîlere yumuşak ve dostça davranmayı, Hâdî’nin sert politikasının etkisini yok etmeyi düşünüyordu. (s. 135)

\section{Teklif Edilen Tercüme}

Hârûnürreşîd, Hz. Ali evlâdına yumuşak olmayı ve Hâdî’nin katı siyasetinin tesirini ortadan kaldırmayı düşünüyordu.

\section{Metnin Aslı}

لثورات الخوارج أساس نظري، و هو عمل بكتاب الله و سنة النبي

\section{Mütercimin Tercümesi}

Hâricîlerin isyanlarının teorik bir temeli vardır. Bu temel, Allah Teâlâ'nın Kitabı'nı ve Peygamber sallallahu aleyhi ve sellem'in sünnetini işletmektir. (s. 137)

\section{Teklif Edilen Tercüme}

Hâricîlerin isyanlarının nazarî bir temeli bulunmaktadır. Bu da; Allah'ın kitabı ve Resûl-i Ekrem'in sünnetiyle amel etmektir.

\section{Metnin Aslı}

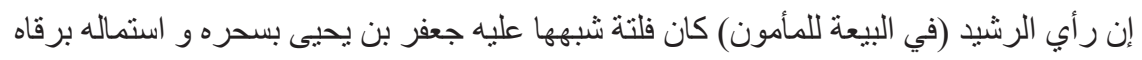

\section{Mütercimin Tercümesi}

Harun Reşîd, (Me'mûn'a biatte) gördüyse Ca ‘fer el-Bermekî’nin sihir yaparak ve efsunlarla ikna ederek karıştırmasına yol açtığı bir sürçme, hata vardı. (s. 168) 


\section{Teklif Edilen Tercüme}

Şüphesiz Hârûnürreşîd'in (Me'mûn’a biat edilmesi hakkındaki) kanaati, Ca'fer b. Yahya'nın sihir ve efsunuyla yönlendirerek karıștırdığı bir hataydı.

\section{Metnin Aslı}

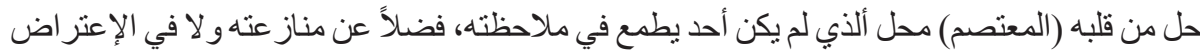
في أمرهو نهيه و إر ادته و حكمه الاعند

\section{Mütercimin Tercümesi}

Onunla çekişme, emrine, yasaklamasına, iradesine ve hükmüne itiraz bir kenara düşüncede bile kimsenin arzulayamayacağı makama onun ( $\mathrm{Mu}$ 'tasım) tarafından getirildi. (s. 234)

\section{Teklif Edilen Tercüme}

Onunla çekişmek, bir işine, yasağına, iradesine veya hükmüne itiraz etmek şöyle dursun; onun (Mu'tasım) kalbinde, kimsenin ilgisini çekmeyi (dahi) umamayacağ bir yer edinmişti.

\begin{tabular}{|l|l|}
\hline Metindeki Kullanım & Doğru Kullanım \\
\hline Horâsân (s. 25) & Horasan \\
\hline Mes'ûdî (s. 57) & Mes'ûdî \\
\hline Umman (s. 67) & Uman \\
\hline Nîsâbûr (s. 90) & Nîşâbur \\
\hline Hayzerân (s. 125) & Hayzürân \\
\hline Sagûr (s. 138) & Sugūr \\
\hline Üşrûsene (s. 213) & Üsrûşene \\
\hline Sehl b. Si/e/ünbât (s. 220) & Sehl b. Simbat \\
\hline Hasan b. Muhalled (s. 257) & Hasan b. Mahled \\
\hline Hâşim b. Abdülmelik (s. 270) & Hişâm b. Abdülmelik \\
\hline Mu'tezid (s. 332) & Mu'tazıd \\
\hline Havârizm (s. 133) & Hârizm \\
\hline Müsteîn (s. 328) & Müstaîn \\
\hline Dimeşk (s. 370) & Dimaşk \\
\hline Ureyb b. Sa‘d (s. 392) & Arîb b. Sa‘d \\
\hline Semilü'l-Kahramâne (s. 387) & Kahramâne Sümel-Semel \\
\hline Yalbak-Yılbak (s. 398) & Yelbak \\
\hline Muhsin (s. 391) & Muhassin \\
\hline
\end{tabular}

